\title{
MULTI-FREQUENCIES PENETRATION LOSS AND MODELING AT 6.5 GHZ TO 38 GHZ FOR 5G COMMUNICATIONS SYSTEM EVALUATION
}

\author{
Nor Raihan Zulkefly', Tharek Abdul Rahman², Marwan Hadri Azmi ${ }^{3}$ \\ ${ }^{1}$ Faculty of Electrical Engineering, Universiti Teknologi Malaysia, 81310, Johor, Malaysia \\ ${ }^{2}$ Faculty of Electrical Engineering, Universiti Teknologi Malaysia, 81310, Johor, Malaysia \\ ${ }^{3}$ Faculty of Electrical Engineering, Universiti Teknologi Malaysia, 81310, Johor, Malaysia
}

\begin{abstract}
High data rate communication is gaining attention to comply user demand, especially in an indoor environment. In a future fifth generation $(5 G)$ communications system, the need for broader spectrum bandwidth motivates the researcher to explore new carrier frequency range from centimetre-wave (cm-Wave) to millimetre-wave (mm-Wave). The paper presents the characterization of penetration loss measurement and modeling for four interior materials typically used in Malaysia building construction, such as concrete, clear glass, tinted glass, and drywall. The measurement campaigns were conducted at 6.5 GHz, $10.2 \mathrm{GHz}, 15 \mathrm{GHz}, 20 \mathrm{GHz}, 28 \mathrm{GHz}$ and $38 \mathrm{GHz}$ in an office environment in Universiti Teknologi Malaysia (UTM- Kuala Lumpur) campus. From the measurements campaign, the result of penetration losses is extracted and modeled. As consequences, it specifies Malaysia building is an environmental friendly for $5 G$ communication due to low attenuation observed compared to existing studies conducted in temperate regions countries. Moreover, the unique characteristic of $15 \mathrm{GHz}$ and $20 \mathrm{GHz}$ distinguished the most potential frequencies for building penetration, especially in Malaysia building environment.
\end{abstract}

Keywords: 5 G communication, Penetration loss, cm-Wave, mm-Wave, interior material, indoor propagation,

\section{INTRODUCTION}

The data traffic of wireless communication has experienced intensely growing spurred by advancement of smartphones and telecommunications gadget. The current LTE/LTE-A system data rate reach several megabits per second, and expected will be increasing tremendously in next decade. Therefore, the data rate, capacity and quality of service for broadband users, has become technically challenging and draw overwhelming of attention among academia and researcher. In order to provide high capacity and data rates communications, the wide range of frequency will be required. Moreover, the major bandwidth shrinking at below $6 \mathrm{GHz}$, motivates the research at higher frequency bands.

Ofcom has identified frequency range between $6 \mathrm{GHz}$ to $100 \mathrm{GHz}$ will be considered for the future 5G communications system. These frequency bands were previously abandoned, due to severe attenuation complied, and insufficiently evaluated for future mobile systems.

Universally, the higher frequency bands are expected disadvantageous as the shorter wavelength will weaken the reflection and diffraction properties of radio wave transmission. However, this criterion otherwise beneficial for small cell and hotspot. In [1][2], the authors agree within $200 \mathrm{~m}$ transmission radii, the communication link is clear of atmospheric attenuation or water vapor absorption.

To model the cm-Wave and mm-Wave channel for indoor environments, the new characterization is required to composite the interior building material properties upon the untested frequency bands.

The study on building materials has been conducted previously. In [3], the comparison of penetration loss from $2 \mathrm{GHz}$ to $74 \mathrm{GHz}$ for glasses and wooden door material was presented. The similar work has been conducted to measure a wide selection of building materials at $2.4 \mathrm{GHz}$ to $5 \mathrm{GHz}$ in [4]. Moreover, the measurement of glasses, concrete, and drywall at $28 \mathrm{GHz}$ in [5], discovered the high losses (> 40 $\mathrm{dB}$ ) is observed at the tinted glass in the urban building, due to highly metal coated for the energy-conserved purpose.

The various concern of building material has been studied in [6], where the properties of penetration, diffraction, and scattering were observed from the view of antenna polarization, material thickness, and permittivity at $40 \mathrm{GHz}$. Interior and exterior wall have been measured at $24 \mathrm{GHz}$ to $31 \mathrm{GHz}$ in [7], indicate the concrete interior wall attenuation range between $10 \mathrm{~dB}$ to $30 \mathrm{~dB}$, while for the exterior wall twice higher than stated values (penetration loss range $20 \mathrm{~dB}$ to $60 \mathrm{~dB}$ ). In [8], the outer wall of the old and modern building have been studied at $0.8 \mathrm{GHz}$ to 28 $\mathrm{GHz}$.

To author's best knowledge, the building material channel characterization measurement has not yet conducted on Southeast Asia building countries specifically, especially at $6 \mathrm{GHz}$ to $38 \mathrm{GHz}$. In this work, we investigate the penetration loss of $\mathrm{cm}$-Wave and mm-Wave channel models 
at for $5 \mathrm{G}$ communications potential frequencies at $6.5 \mathrm{GHz}$ to $38 \mathrm{GHz}$. Four materials have been measured such as concrete, clear glass, tinted glass, and drywall to contribute to the fundamental information of material characterization on high frequencies. The result reveals the penetration loss are relatively dependent on the frequency bands, nevertheless the unique characterization at $15 \mathrm{GHz}$ and 20 $\mathrm{GHz}$ indicate special behavior in channel propagations. Furthermore, based on the measurement results, the penetration loss models are proposed.

The remainder of the paper is organized as follows: The equipment setting is presented in Section II, measurement environment and measurement procedures are presented in Section III. Section IV presents the result of measurement and modeling for the materials measured. Finally, Section V concludes the paper.

\section{MEASUREMENT SETUP}

$0 \mathrm{dBm}$ of continuous-wave RF signal was generated by Anritsu MG369xC Signal Generator and delivered to pyramidal horn antenna. On the RX side, the received power signal is captured by pyramidal horn antenna and measured using Anritsu MS2720T handheld spectrum analyzer. The gain for vertically-polarized configuration antennas are 12 $\mathrm{dBi}, 12 \mathrm{dBi}, 14 \mathrm{~dB}, 13 \mathrm{dBi}, 19.2 \mathrm{dBi}$ and $21.2 \mathrm{dBi}$ for 6.5 $\mathrm{GHz}, 10.2 \mathrm{GHz}, 15 \mathrm{GHz}, 20 \mathrm{GHz}, 28 \mathrm{GHz}$ and $38 \mathrm{GHz}$ respectively.

\section{ENVIRONMENT DESCRIPTION}

AND EXPERIMENTAL PROCEDURE

Measurements campaign were conducted in Malaysia-Japan International Institute of Technology (MJIIT) building, in UTM-Kuala Lumpur, which is a 10-story building constructed early 1990's. The building is typical office environment, consist of classroom, hallway, cubicle partition, elevator etc. building interior is composed of reinforced concrete, metal, clear glass and tinted glasses.

For this work, the TX and RX are positioned to each other boresight, at $1.5 \mathrm{~m}$ height above the floor, perpendicular to the material under test (MUT). The distance from TX to MUT and MUT to RX are set to $2.5 \mathrm{~m}$ between TX to MUT and MUT to RX. For unobstructed case, the distance between antennas is set to $5 \mathrm{~m}$ as given in Figure 1. Four common interior MUTs were studied in this work, a) concrete wall of $23 \mathrm{~cm}$ thick, b) clear glass of $1.5 \mathrm{~cm}$ thick, c) tinted glass of $1.75 \mathrm{~cm}$ thick, and d) drywall of $2 \mathrm{~cm}$ as depicted in Figure 2 . Since the transmitted power was a single tone, the material penetration loss (PLm) is easier to be evaluated of aforementioned material can be calculated as follows:

$$
\operatorname{Lm}(d B)=\operatorname{Prm}(d B m)-\operatorname{Prsf}(d B m)
$$

Where PLm is material penetration loss (in $\mathrm{dB}$ ), Prm is received power with MUT, and Prsf is received power in the unobstructed path (free-space), both in $\mathrm{dBm}$ unit.

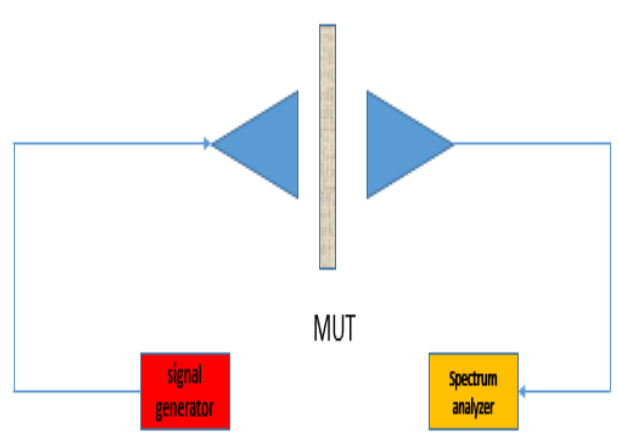

(a)

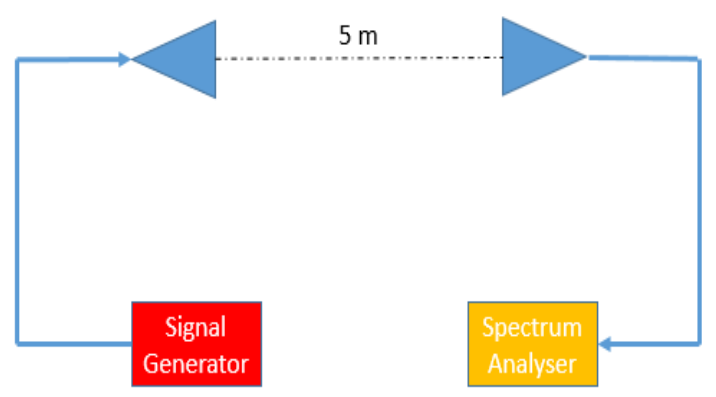

(b)

Fig -1: Overview of penetration loss measurement with (a) obstacle and (b) in free-space.

Table 1: Material under test thickness

\begin{tabular}{|l|l|}
\hline Material & Thickness $[\mathrm{cm}]$ \\
\hline Concrete & 23.2 \\
\hline Clear glass & 1.5 \\
\hline Tinted glass & 1.6 \\
\hline Drywall & 2 \\
\hline
\end{tabular}

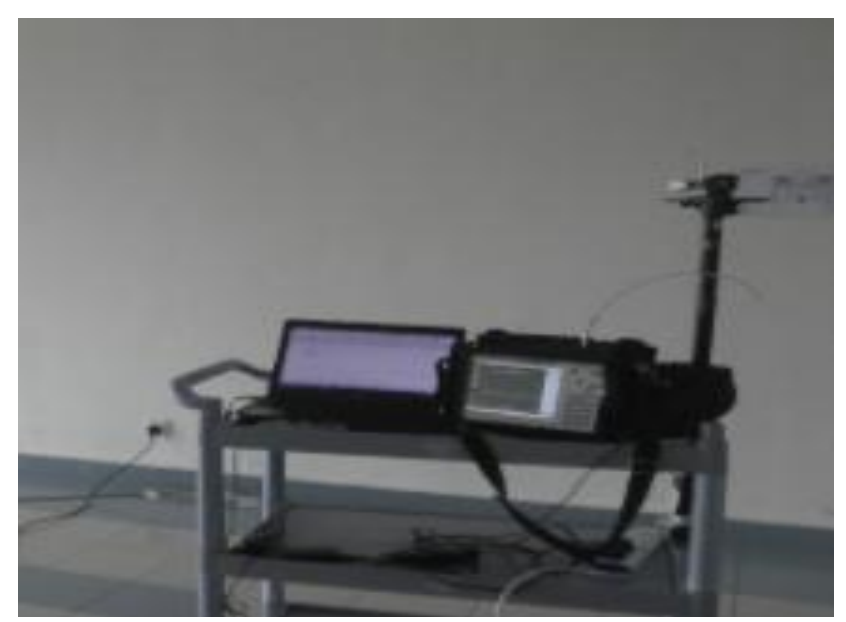

(a) Concrete wall 


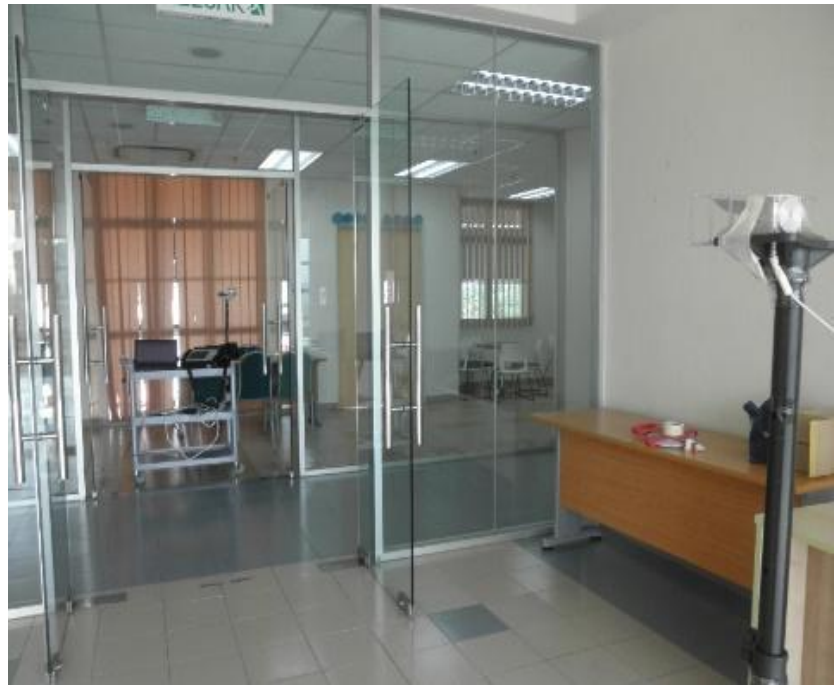

(b) Clear glass

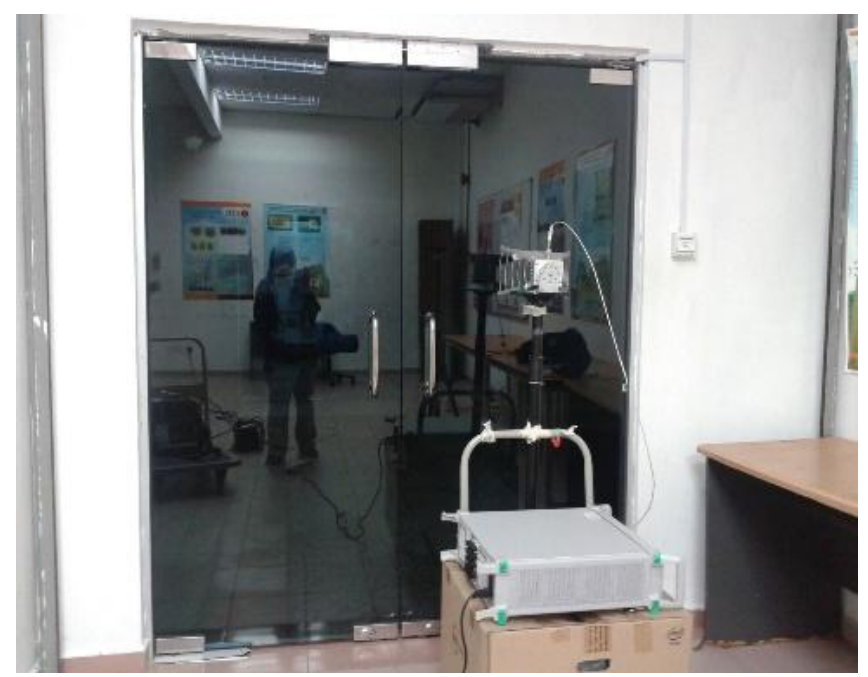

(c) Tinted glass

Fig.-2The sample of material under test (MUT) on (a) concrete, (b) clear glass and (c) tinted glass.

\section{MATERIAL PENETRATION LOSS MODELS}

To evaluate the penetration loss of interior material over diversities of frequency, material path loss model is given as follows [3][9] :

$$
P L \quad(d B)=a+n * f(G H z)+X \sigma
$$

Where $a$ is intercept and $n$ is gradient, and $f(G H z)$ is the frequency in $\mathrm{GHz}, X \sigma$ is zero-mean Gaussian variable with standard deviation $\sigma$ in $\mathrm{dB}$.

\section{NUMERICAL RESULTS AND DISCUSSION}

The numerical result for penetration loss for building interior material as given in Figure 3- Figure 6 as follows:

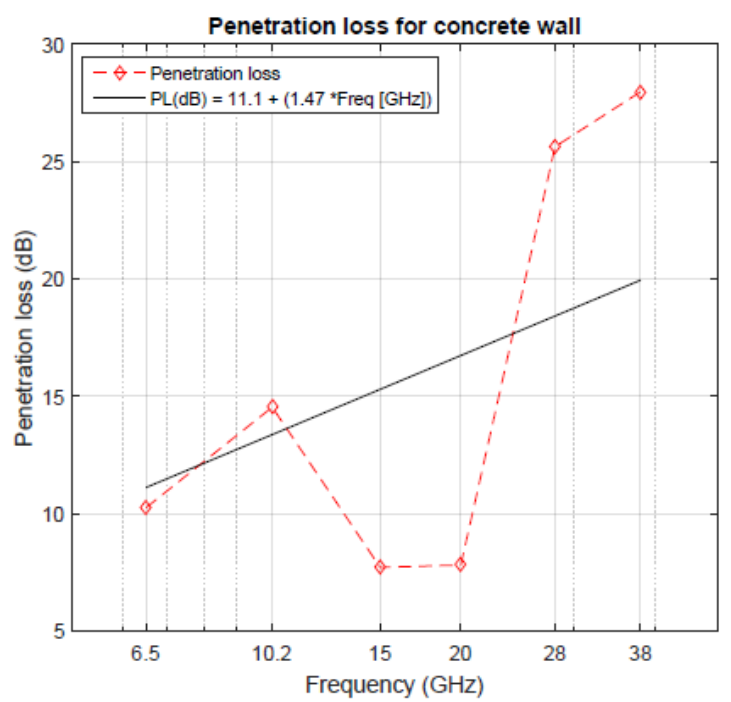

Fig-3Penetration loss of concrete wall

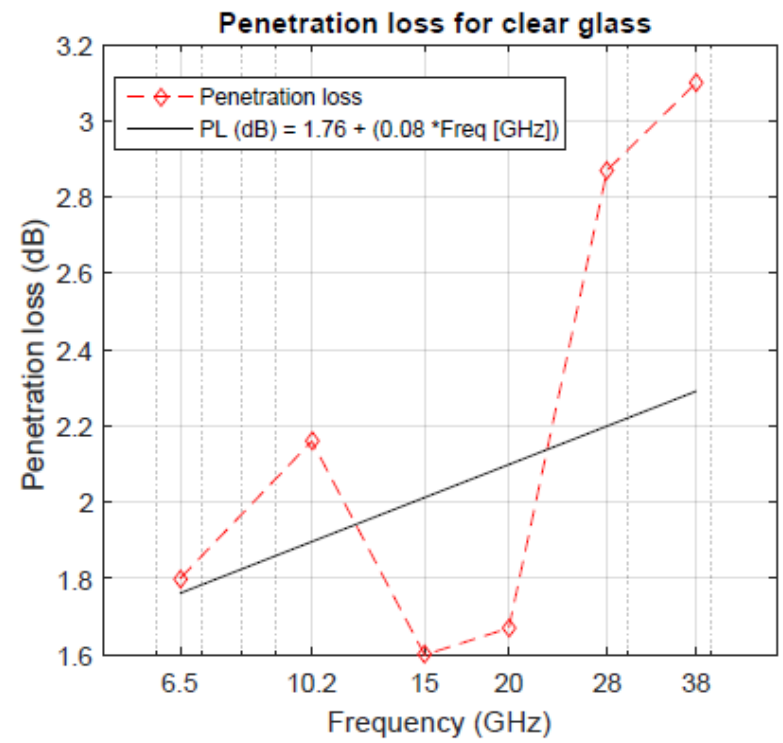

Fig- 4 Penetration loss of clear glass door

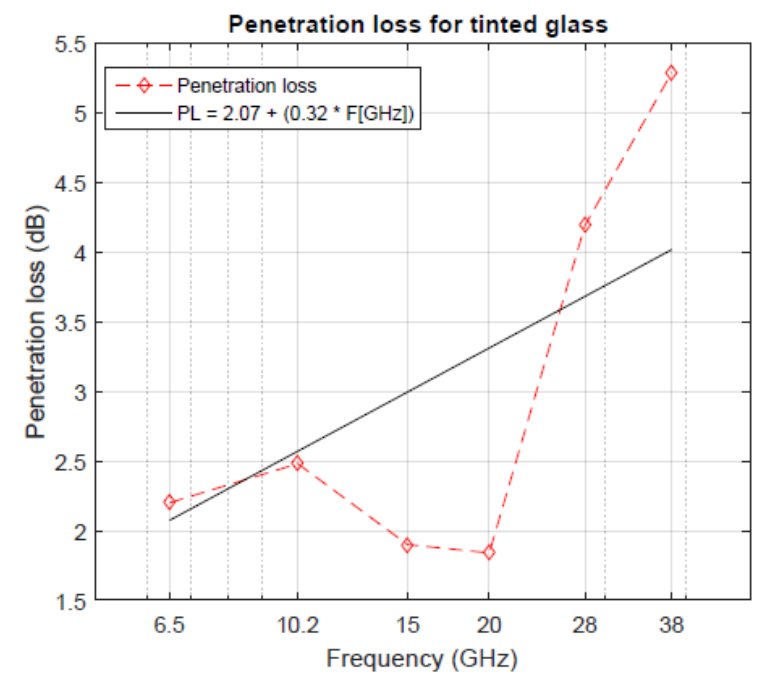

Fig -5 Penetration loss of tinted glass wall 


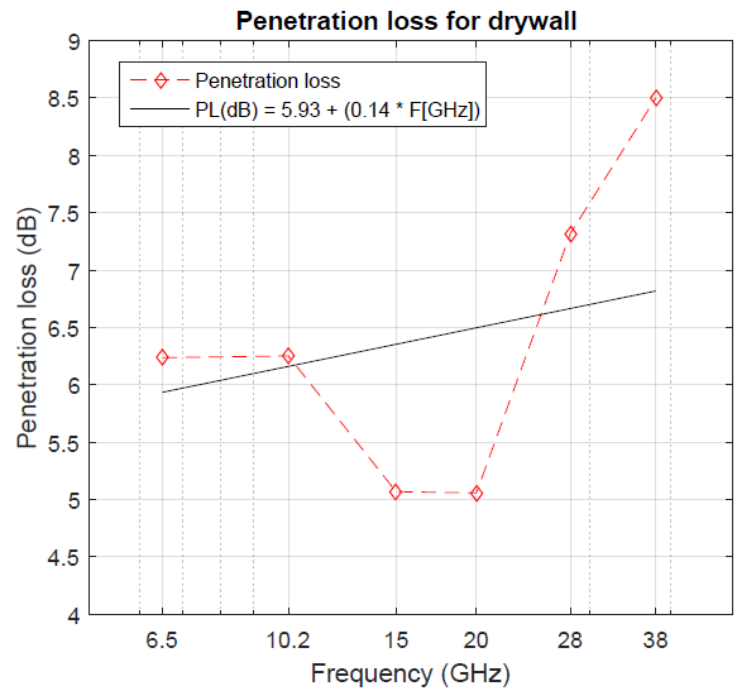

Fig-6 Penetration loss of drywall

At the glance, it can be seen that the penetration losses are relatively increasing as the frequency increase, from 6.5 $\mathrm{GHz}, 10.2 \mathrm{GHz}, 28 \mathrm{GHz}$ and $38 \mathrm{GHz}$. Otherwise, the significant penetration losses degraded at $15 \mathrm{GHz}$ and 20 $\mathrm{GHz}$ for all measured materials respectively.

The range of penetration loss at $15 \mathrm{GHz}$ and $20 \mathrm{GHz}$ are 7.7 $\mathrm{dB}$ to $7.8 \mathrm{~dB}$ for concrete, $1.61 \mathrm{~dB}$ to $1.67 \mathrm{~dB}$ for clear glass, $1.9 \mathrm{~dB}$ to $1.84 \mathrm{~dB}$ for tinted glass and $5.06 \mathrm{~dB}$ for drywall respectively.

For $6.5 \mathrm{GHz}$ and $10.2 \mathrm{GHz}$, the moderate penetration is perceived $10.25 \mathrm{~dB}$ to $14.53 \mathrm{~dB}$ for concrete, $1.8 \mathrm{~dB}$ to 2.16 $\mathrm{dB}$ for clear glass, $2.2 \mathrm{~dB}$ to $2.48 \mathrm{~dB}$ for tinted glass and 6.2 $\mathrm{dB}$ for drywall respectively.

On the other hand, $28 \mathrm{GHz}$ and $38 \mathrm{GHz}$ indicate the highest penetration loss of $25.6 \mathrm{~dB}$ to $27.96 \mathrm{~dB}$ for concrete, 2.87 $\mathrm{dB}$ to $3.1 \mathrm{~dB}$ for clear glass, $4.19 \mathrm{~dB}$ to $5.29 \mathrm{~dB}$ for tinted glass and $7.32 \mathrm{~dB}$ to $8.5 \mathrm{~dB}$ for drywall respectively.

The smaller wavelength of a frequency (especially at 28 $\mathrm{GHz}$ and $38 \mathrm{GHz}$ ) would weaken the reflectivity and diffraction through the wall, or object. Thus, critically high losses observed, particularly at high thickness materials. While the lower frequency bands (i.e: $6.5 \mathrm{GHz}$ and 10.2 $\mathrm{GHz}$ ) are estimated to provide better penetration through the materials. $28 \mathrm{GHz}$ and $38 \mathrm{GHz}$ are believed to be great potential frequency bands for indoor small cell or secure hotspot network.

In the case of $15 \mathrm{GHz}$ and $20 \mathrm{GHz}$, due to excessive radio frequency $(\mathrm{RF})$ penetration, these bands are reliable to accommodate for outdoor-to-indoor (O2I) propagation link, where the major reflectivity and diffraction are required to support indoor network. As this work is measured in Kuala Lumpur building only, the requirement might be different for other countries.

Comparing between four materials measured in this work, the high thickness of material cause to high penetration losses. As seen in Table 2, the penetration loss exponent is highest on the concrete of 1.47 , follow by $1.4,0.3$ and 0.08 for drywall, tinted glass, and clear glass respectively.

However, as the existing study reported in [6] indicate the penetration loss recorded for concrete wall widely varies $(175 \mathrm{~dB}$ at $40 \mathrm{GHz}$ ) to the recorded in this work (see Figure 6 ). We believed that building in temperate regions countries is differently constructed from Southeast Asia countries, particularly due to thickness, and concrete materials [10][13] .

The similar case observed for tinted glass, which is apparently higher $(24.5 \mathrm{~dB})$ at $28 \mathrm{GH}$ in [5], compared to $1.9 \mathrm{~dB}$ to $5.29 \mathrm{~dB}$ in this work. High penetration losses at temperate region countries are due high metal-coated tinted glass, for the purpose of energy-efficiency building, whereas the criterion is a disregard for the measured clear glass in this work. The tinted glass in Southeast Asia countries is typically made by the thin tinted film.

On the hand, the similar characterization is seen on clear glass materials. While slightly lower penetration loss for drywall of existing study, due to the lower thickness compared to material measured in this work.

Table -2: Penetration fit result

\begin{tabular}{|l|l|l|l|}
\hline Material & $\alpha(\mathrm{dB})$ & $\mathrm{n}$ & $\mathrm{X} \sigma(\mathrm{dB})$ \\
\hline Concrete & 11.11 & 1.47 & 9.01 \\
\hline Clear glass & 1.76 & 0.08 & 0.64 \\
\hline Tinted glass & 2.07 & 0.3 & 1.42 \\
\hline Drywall & 5.93 & 0.14 & 1.32 \\
\hline
\end{tabular}

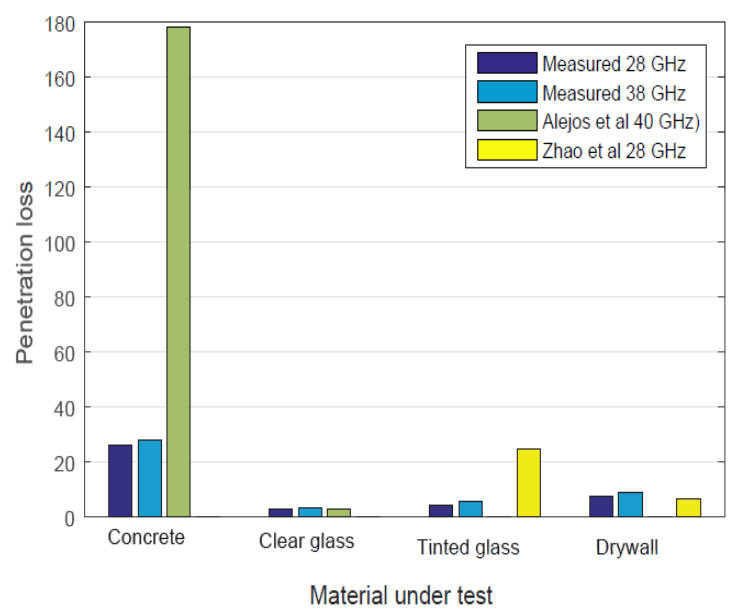

Fig- 7: Comparison to other work at similar frequency bands. Source [6][5].

\section{CONCLUSION}

The typical building interior materials are studied in this work. The penetration losses of concrete, clear glass, tinted glass, and drywall are measured, and model at $6.5 \mathrm{GHz}$ to $38 \mathrm{GHz}$ frequency bands, for a $5 \mathrm{G}$ communication system. 
In this work, the similar material at similar frequency ranges are compared to existing study, indicated the concrete and tinted glass commonly used in Southeast Asia countries are utmost reliable to penetrate RF at higher frequency bands , compared to temperate region countries. Moreover, it found the uniquely characterized of $15 \mathrm{GHz}$ and $20 \mathrm{GHz}$ for indoor penetration, discovered new potential frequency bands for Malaysia 5G communication spectrum allocation.

\section{REFERENCES}

[1] T. S. Rappaport, S. H. U. Sun, R. Mayzus, H. Zhao, Y. Azar, K. Wang, G. N. Wong, J. K. Schulz, M. Samimi, and F. Gutierrez, "Millimeter Wave Mobile Communications for 5G Cellular: It Will Work!," IEEE Access, vol. 1, pp. 335-349, 2013.

[2] Sulyman, A. Nassar, M. Samimi, G. Maccartney, T. Rappaport, and A. Alsanie, "Radio propagation path loss models for $5 \mathrm{G}$ cellular networks in the $28 \mathrm{GHZ}$ and 38 GHZ millimeter-wave bands," IEEE Commun. Mag., vol. 52, no. 9, pp. 78-86, 2014.

[3] Y. Du, C. Cao, X. Zou, J. He, H. Yan, G. Wang, and D. Steer, "Measurement and modeling of penetration loss in the range from $2 \mathrm{GHz}$ to $74 \mathrm{GHz}, " 2016$ IEEE Globecom Work. (GC Wkshps), pp. 0-5, 2016.

[4] R. Wilson, "Propagation Losses Through Common Building Materials $2.4 \mathrm{GHz}$ vs $5 \mathrm{GHz}$," 2002.

[5] H. Zhao, R. Mayzus, S. Sun, M. Samimi, J. K. Schulz, Y. Azar, K. Wang, G. N. Wong, F. Gutierrez, and T. S. Rappaport, " $28 \mathrm{GHz}$ Millimeter Wave Cellular Communication Measurements for Reflection and Penetration Loss in and around Buildings in New York City," 2013 Int. Conf. Commun., no. Icc, 2013.

[6] V. Alejos, M. G. Sanchez, and I. Cuinas, "Measurement and analysis of propagation mechanisms at $40 \mathrm{GHz}$ : Viability of site shielding forced by obstacles," IEEE Trans. Veh. Technol., vol. 57, no. 6, pp. 3369-3380, 2008.

[7] Guo, Y. Wu, J. Jiao, B. Lv, F. Zhou, Z. Ma, and J. Sun, "Building Entry Loss Model for 24 to $31 \mathrm{GHz}$ band," in 2016 International Symposium on Antennas and Propagation (ISAP), 2016, no. 1, pp. 60-61.

[8] Rodriguez, H. Nguyen, T. Sorensen, I. Kovacs, and P. Mogensen, "An Empirical Outdoor-to-Indoor Path Loss Model from below $6 \mathrm{GHz}$ to cm-Wave Frequency Bands," IEEE Antennas Wirel. Propag. Lett., pp. 1-1, 2016.

[9] E. Semaan, F. Harrysson, A. Furuskar, and H. Asplund, "Outdoor-to-indoor coverage in high frequency bands," 2014 IEEE Globecom Work. GC Wkshps 2014, pp. 393-398, 2015.

[10] G. C. Gifford, National Structural Concrete Specification for Building Construction. 2009.

[11] D. O. R. S. Chong, "APEC Building Codes, Regulations, and Standards: Minimum, Mandatory and Green,” p. 227, 2013.

[12] B. Ir and L. Char, "Provisions In Design Codes : Are They Really Adequate?," pp. 9-12, 1997.
[13] ACI Committee 318, "Building Code Requirements for Reinforced Concrete," ACI Struct. J., vol. 552, no. d, p. 503, 2011.

\section{BIOGRAPHIES}

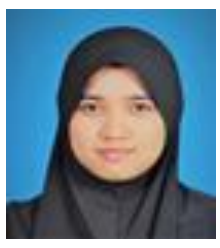

Nor Raihan Zulkefly (Student, IEEE) obtained her Bachelor Degree of Data Communication in 2010. In 2012 she obtained her MEng. in Electrical/ Electronic and System majoring in Computer and Communication from National University of Malaysia (UKM). Currently she pursues her study as PhD. candidate in Universiti Teknologi Malaysia (UTM). Her research interest is include but not limited to wireless radio propagation in $5 \mathrm{G}$, interference management of LTE and LTE-Advanced and relay technique in LTE-Advanced.

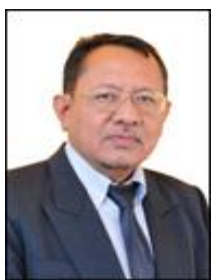

Tharek Abd Rahman (Member, IEEE) is a Professor at Faculty of Electrical Engineering, Universiti Teknologi Malaysia (UTM). He obtained his BSc. in Electrical \& Electronic Engineering from University of Strathclyde UK in 1979, MSc in Communication Engineering from UMIST Manchester UK and $\mathrm{PhD}$ in Mobile Radio Communication Engineering from University of Bristol, UK in 1988. He is the Director of Wireless Communication Centre (WCC), UTM. His research interests are radio propagation, antenna and RF design and indoors and outdoors wireless communication. He has published more than 300 papers related to wireless communication in national/international journal and conference.

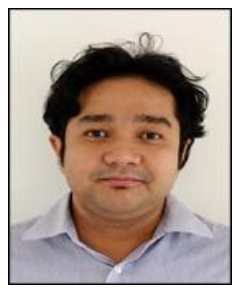

Marwan Hadri Azmi received the B.Eng. (Hons Class I) degree in electrical and telecommunications from the Universiti Teknologi Malaysia in 2003, the M.Sc. degree in communications and signal processing from the Imperial College of Science, Technology and Medicine, University of London in 2005, and the Ph.D. degree from the University of New South Wales, Australia, in 2012. He is currently a senior lecturer at Wireless Communication Centre, Universiti Teknologi Malaysia. From 2012 to 2014, he spent his Sabbatical leave of absence at the McGill University, Canada, working in the funded project by RIM Inc. and NSERC, entitled "Cooperative Spectrum Sensing and Information Relaying in Cognitive Wireless Communications". His research interests include mobile and wireless communications, communication theory, error control coding, relay networks, spectrum sensing for cognitive radio, and iterative receiver. 